\title{
Cell Growth in Aggregates Determines Gene Expression, Proliferation, Survival, Chemoresistance, and Sensitivity to Immune Effectors in Follicular Lymphoma
}

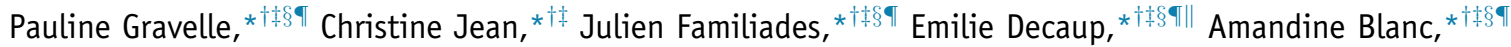

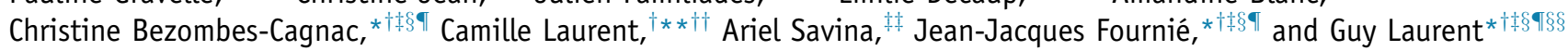

From the National Institute of Health and Medical Research (INSERM) UMR1037-Cancer, * Research Center of Toulouse, Toulouse; University of Toulouse III: Paul Sabatier, ${ }^{\dagger}$ Toulouse; the National Center for Scientific Research ERL 5294, ${ }^{\ddagger}$ Toulouse; the Carnot Lymphoma Institute (CALYM), ${ }^{\S}$ Toulouse; the Laboratoire d'Excellence Toulouse Cancer: TOUCAN, "Toulouse; the Roche Research Institute," Boulogne Billancourt; INSERM UMR1047,** Center for Pathophysiology of Toulouse Purpan, Toulouse; the Departments of Anatomopathology ${ }^{\dagger \dagger}$ and Hematology, ${ }^{\S \S}$ Hospital Purpan, Toulouse; and S.A.S. Roche, ${ }^{\ddagger \dagger}$ Boulogne Billancourt, France

Accepted for publication

September 26, 2013.

Address correspondence to Pauline Gravelle, Ph.D., Cancer Research Center of Toulouse Equipe 9, CHU Purpan, 31024 Toulouse cedex 3, France. Email: pauline.gravelle@inserm. fr or paulinegravelle@hotmail. com.

\begin{abstract}
Lymphomas grow as dense aggregates in patients, but whether this spatial organization affects lymphoma cell biology is unknown. We grew follicular lymphoma (FL) cells in vitro as multicellular aggregates of lymphoma cells to investigate this question. Gene expression analysis revealed that 612 genes were differentially expressed when cells grew in multicellular aggregates of lymphoma cells rather than in suspension. These genes correspond to several GO biological processes, such as hypoxia, activation of NF- $\kappa B$ pathway, and negative regulation of cell cycle, a gene signature also found in the transcriptomes from FL biopsies. Pimonidazole staining, HIF-1A accumulation, and VEGFA release confirmed that cells in multicellular aggregates of lymphoma cells actually respond to hypoxia. In adaptation to such conditions, they also displayed an activated NF- $\kappa$ B pathway and a quiescent status far more frequently than in suspension. When cultured in three dimensions, FL cells display resistance to doxorubicin and bendamustine, two drugs largely used in FL therapy, compared to FL cultured in suspension. Finally, multicellular aggregates of lymphoma cells were also found to be less sensitive to purified natural killer cells. To conclude, our study shows that in $\mathrm{FL}$, spatial organization results in dramatic changes in FL biology, including gene expression, proliferation, drug resistance, and immune escape. (Am J Pathol 2014, 184: 282-295; http://dx.doi.org/10.1016/j.ajpath.2013.09.018)
\end{abstract}

Non-Hodgkin lymphomas represent a large group of cancers, with 75,190 new cases in the United States in 2011, with diffuse large B-cell lymphomas and follicular lymphomas (FL) the most frequent subtypes. In the last decade, patients with FL have benefited from the introduction of immunochemotherapy consisting of the association of genotoxic agents such as doxorubicin with rituximab, a chimeric monoclonal antibody directed against the membrane-associated CD20 antigen. FL is still generally considered an incurable disease, however, justifying further investigations of the molecular and cellular basis of its natural history and chemosensitivity.

This disease is characterized by a low proliferation rate and subsequent slow tumor cell accumulation, natural chemoresistance reflected by relatively low incidence of molecular response to immunochemotherapy (about 50\%), and immune escape illustrated by inevitable relapse even after complete remission, suggesting that immune effectors, including natural killer (NK) cells, are inefficient in eradicating minimal residual disease. However, the molecular basis of all these features remains to be elucidated, although

\footnotetext{
Supported by institutional grants from the Institut National de la Santé et de la Recherche Médicale (INSERM), the Université Paul Sabatier, and Centre National de la Recherche Scientifique (CNRS). The authors have received funding contracts from Institut National du Cancer (RITUXOP), Institut Carnot-Lymphome (CALYM), and Fondation de France (2009002593).

P.G. and C.J. contributed equally to this work.

Current address of C.J., Department of Reproductive Medicine, Moores Cancer Center, University of California, San Diego, San Diego, CA.
} 
the $\mathrm{t}(14,18)$ and subsequent $\mathrm{Bcl}-2$ overexpression has been shown to play a role in drug resistance and perhaps in negative regulation of cell proliferation. ${ }^{1,2}$

To address such questions, however, most in vitro studies so far have involved cell suspensions that are not representative of the carcinoma-like architecture of FL spherical tumors in vivo. The three-dimensional (3D) organization of spheroid carcinomas drives proliferation and survival adaptations by harnessing gene expression and signaling pathways to high cell density, stress, hypoxia, and low access to nutrients. ${ }^{3,4}$ Further studies have shown that spatial organization confers intrinsic tumor cell resistance to genotoxic compounds, ${ }^{5}$ as well as to ionizing radiation, because of hypoxia. ${ }^{6}$ Finally, growth in aggregates results in decreased sensitivity to immune effectors such as cytotoxic T lymphocytes. ${ }^{7-9}$

We designed a novel method of 3D in vitro culture of non-Hodgkin lymphoma cells to generate multicellular aggregates of lymphoma cells (MALC), and used these as a model to address such questions. Investigating the biological characteristics of FL cells grown in MALC revealed for the first time that this spatial organization deeply affects gene expression, cell proliferation, and survival as an adaptation to hypoxic conditions and beyond, to chemotherapeutic drugs and NK cells.

\section{Materials and Methods}

\section{Cell Lines and Reagents}

The $\mathrm{t}(14,18)^{+}$FL ATCC RL cell line (ATCC, Manassas, VA) was cultured at $37^{\circ} \mathrm{C}$ in humidified $5 \% \mathrm{CO}_{2}$ in complete medium. Hypoxia experiments were performed in a hypoxic chamber $\left(0.1 \% \mathrm{O}_{2}\right)$ or with $10 \mu \mathrm{mol} / \mathrm{L}$ cobalt chloride $\left(\mathrm{CoCl}_{2}\right)$. PKH67 and plasmids were obtained from Sigma-Aldrich (St. Louis, MO). Vascular endothelial growth factor A (VEGFA) concentrations were determined by using the QIA51 ELISA (enzyme-linked immunosorbent assay) kit (Merck Millipore, Molsheim, France).

Peripheral blood mononuclear cells were collected from healthy donors (Etablissement Français du Sang, CHU Purpan, Toulouse) and separated by Ficoll-Hypaque density gradient (GE Healthcare, Little Chalfont, UK). Negative selection of NK cells was performed with the EasySep Human NK Cell Enrichment Kit, according to the manufacturer's instructions (STEMCELL Technologies, Grenoble, France). The purity of the enriched NK cells (around 95\%) was evaluated by flow cytometry using a CD56-PE-Cy5 antibody (BD Biosciences, le Pont de Claix, France) and a CD3-PECy7 antibody (Beckman Coulter, Roissy, France).

\section{Multicellular Aggregates of Lymphoma Cells}

MALC were produced by an adaptation of the hanging drop method. ${ }^{10}$ Cell suspensions $(500,000$ cells $/ \mathrm{mL})$ were prepared in complete medium containing $1 \%$ Methocult (STEMCELL Technologies), and $20 \mu \mathrm{L}$ of this suspension were dropped onto coverslips of a 24-well culture plate. After 24 hours incubation, all drops were transferred by returning the coverslip to a dish previously coated with $1 \%$ agarose (Invitrogen, Saint Aubin, France). All of the MALC culture medium was then renewed every 5 days. The number of cells in MALC was estimated by trypan blue counting; their volume $(\mathrm{V})$ was calculated by measuring two diameters $(\mathrm{L}=$ longest diameter and $\mathrm{l}=$ shortest diameter $)$ and using the formula:

$$
\mathrm{V}=4 / 3 \times \pi \times \mathrm{L} \times 1^{2} / 2^{3} .
$$

\section{Cell Imaging}

RL cells were stained by PKH67 (Sigma-Aldrich) before MALC preparation. Samples were kept in culture medium at room temperature during acquisitions. MALC were visualized on the fluorescein channel of a LSM 7 MP Laser Scanning biphoton microscope (Zeiss, Le Pecq, France), with $20 \times$ plan apochromat objective, numerical aperture $=$ 1 , dry. Series of 90 to $150 \mathrm{z}$-sections were taken at $1-\mu \mathrm{m}$ distance. Images were produced with ZEN-2008-LE software (Zeiss) and analyzed with Imaris version 3.1 3D software (Bitplane, Zurich, Switzerland).

\section{Western Blot Analysis}

MALC were dissociated, washed with PBS, lysed in Cytobuster (Merck Millipore), and Western blot analysis was performed as described. ${ }^{11}$ Antibodies used were against $\alpha$ tubulin (Sigma-Aldrich), $\beta$-actin (Millipore, Saint-Quentinen-Yvelines, France), hypoxia-inducible factor 1- $\alpha$ (HIF1A) (Cayman Biochem, Montluçon, France), phospho-Ser536

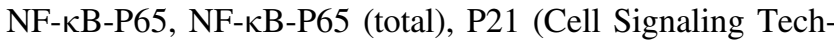
nology, Saint-Quentin-en-Yvelines, France), P27 (Santa Cruz Biotechnology, Le-Perray-en-Yvelines, France), origin recognition complex (ORC2) (MBL International, Woburn, MA), and peroxidase-conjugated secondary anti-rabbit or anti-mouse Ig (Jackson ImmunoResearch Laboratories, Montluçon, France). Cell fractionation has been described elsewhere. $^{12}$

\section{Flow Cytometry}

All stained cells were analyzed with a LSRII flow cytometer (BD Biosciences), and data were processed using DIVA version 6.1.2 software (BD Biosciences).

\section{Phenotype}

MALC were dissociated in PBS by mechanical force; cells were then washed with cold PBS and stained with the following fluorochrome-conjugated antibodies; briefly, phycoerythrin (PE)-conjugated intercellular adhesion molecule (ICAM; CD54) (Beckman Coulter), fluorescein isothiocyanate (FITC)-conjugated human leukocyte antigen (HLA)-ABC, PE-conjugated HLA-E (eBiosciences, Paris, 
France), and FITC-conjugated FAS antibody (Beckman Coulter) were incubated on cells for 20 minutes at $4{ }^{\circ} \mathrm{C}$, and then washed with cold PBS prior to analysis by flow cytometry.

\section{Degranulation Assay and CD107a Expression}

For the degranulation assay, MALC cells or RL cells in suspension were harvested and incubated at $37^{\circ} \mathrm{C}$ with $\mathrm{NK}$ cells at a 1:1 ratio for 4 hours. Reactions were stopped on ice, and cells were stained with fluorochrome-conjugated anti-human CD107a (BD Pharmingen; BD Biosciences) or isotype-matched control antibody in staining buffer containing $1 \%$ fetal calf serum. Fluorescence was analyzed by flow cytometry.

\section{Pimonidazole Assay}

Oxygen deprivation was measured with a Hypoxyprobe-1 Plus Kit (NPI Inc, Burlington, MA). MALC were incubated in medium containing $100 \mu \mathrm{mol} / \mathrm{L}$ pimonidazole for 2 hours at $37^{\circ} \mathrm{C}$, and then dissociated, washed, fixed with $2 \%$ paraformaldehyde for 15 minutes at room temperature, washed again, and finally incubated for 20 minutes with $1 \%$ FITC-conjugated anti-pimonidazole antibody.

\section{5-Bromo-2-Deoxyuridine Incorporation Assay and Cell-Cycle Analysis}

MALC medium was replaced by medium containing 10 $\mu \mathrm{mol} / \mathrm{L}$ 5-bromo-2-deoxyuridine (BrdU) and incubated 1 hour at $37^{\circ} \mathrm{C}$, MALC were then dissociated and washed (PBS $0.5 \%$ bovine serum albumin). Ice-cold ethanol (100 $\mu \mathrm{L}$ ) was added to cells and incubated (20 minutes at room temperature). Cells were washed and incubated in $500 \mu \mathrm{L}$ of $2 \mathrm{~mol} / \mathrm{L} \mathrm{HCl}$ buffer (20 minutes at room temperature) before incubation (5 minutes) with $0.1 \mathrm{~mol} / \mathrm{L} \mathrm{Na}_{2} \mathrm{~B}_{4} \mathrm{O}_{7}(\mathrm{pH} 8.5$ ). Anti-BrdU-FITC (BD Biosciences) was added to cells (20 minutes at room temperature). Cells were then washed twice and incubated (30 minutes at room temperature in the dark) with $10 \mu \mathrm{g} / \mathrm{mL}$ propidium iodide (Invitrogen) and $500 \mu \mathrm{g} /$ $\mathrm{mL}$ RNase A (Invitrogen).

\section{High-Resolution Cell-Cycle Analysis}

Quiescent cells were detected by a high-resolution cell-cycle analysis technique. ${ }^{13}$ After fixation (20 minutes at room temperature in ice-cold ethanol), cells were stained for KI-67 (clone Ki-67; BioLegend, Saint Quentin en Yvelines, France), washed, and then labeled with 7-AAD (BD Biosciences) for 30 minutes at room temperature to visualize their DNA content. The raw percentages from cytometry are shown as ratios: induction of quiescence (fold change $)=(\%$ quiescent among treated cells $) /(\%$ quiescent among untreated cells).

\section{Cell-Cycle Fractionation}

We used a cell-cycle fractionation technique ${ }^{14}$ to sort the quiescent and cycling viable cells from MALC. The DNA content were stained with $10 \mu \mathrm{g} / \mathrm{mL}$ Hoechst 33342 (Invitrogen) for 45 minutes at $37^{\circ} \mathrm{C}$, washed, and then stained with $2 \mu \mathrm{mol} / \mathrm{L}$ pyronin $\mathrm{Y}$ (Sigma-Aldrich) for 45 minutes at $37^{\circ} \mathrm{C}$. Quiescent cells are pyronin $\mathrm{Y}^{\text {dull }}$ and Hoechst ${ }^{2 \mathrm{n}}$, whereas proliferating cells are pyronin $\mathrm{Y}^{\text {bright }}$. To sort cells for culture, this technique was replaced by a single pyronin Y staining. Drug sensitivity of both types of cells was evaluated by trypan blue counting.

\section{Cytotoxicity Assay}

The sensitivity of cells to NK cytotoxicity was measured by a conventional 4-hour ${ }^{51} \mathrm{Cr}$ release assay by using triplicate cultures in round-bottom 96-well plates. Target cells $\left(1 \times 10^{6}\right.$ cells) (suspension RL cells or cells dissociated from MALC) were labeled with $100 \mu \mathrm{Ci}$ of ${ }^{51} \mathrm{Cr}$ (sodium chromate, $1 \mathrm{mCi}$ / $\mathrm{mL}$; PerkinElmer, Courtaboeuf, France). After 1-hour incubation at $37^{\circ} \mathrm{C}$, cells were washed three times in RPMI. NK effector cells were added to ${ }^{51} \mathrm{Cr}$-labeled target cells in replicate at various effector-to-target ratios (10:1, 5:1, 2.5:1, and 1.25:1) in a total volume of $200 \mu \mathrm{L}$ of RPMI containing $5 \%$ fetal calf serum per well of 96-well round-bottomed microtiter plates. Microtiter plates were centrifuged at 300 $\times g$ for 5 minutes and incubated at $37^{\circ} \mathrm{C}$. After 4 hours of culture, $50 \mu \mathrm{L}$ of cell-free supernatants were transferred to a LumaPlate microplate (PerkinElmer), and the radioactivity was measured on a TopCount microplate scintillation and luminescence counter (PerkinElmer). The specific cytotoxicity was calculated. Spontaneous release was determined from wells containing target cells alone. Maximum release was determined from wells containing target cells lysed in $1 \%$ Triton X-100. Percent-specific cytotoxicity was calculated conventionally as described earlier.

\section{Immunohistochemistry of MALC}

Aggregates were transferred in agarose-precoated transwells (R\&D Systems, Lille, France). Medium was replaced by $10 \%$ buffered formalin for fixation; MALC were embedded in agarose and then in paraffin. Immunostaining was performed on sections obtained with an automated stainer (Ventana Medical Systems, Tucson, AZ). Antibodies used were antiKi-67 (clone MIB-1; BioLegend) and anti-pimonidazole (NPI). After incubation with antibodies, sections were incubated with the avidin-biotin-peroxidase complex (Vector Laboratories, Burlingame, CA) followed by staining with diaminobenzidine (DAB) chromogen solution.

\section{Lentivector Production and RL Cell Transduction}

The pLKO.1-puro-CMVTagFP635 vector was used for all transduction experiments. HIFIA gene inhibition used the 
Table 1 Sequences Used for HIF1A Gene Inhibition (sh3810 and sh10819) and Control (shc013)

\begin{tabular}{ll}
\hline shRNA & Sequence \\
\hline sh3810 & $5^{\prime}$-CCGGGTGATGAAAGAATTACCGAATCTCGAGATTCGGTAATTCTTTCATCACTTTTT-3' \\
sh10819 & $5^{\prime}$-CCGGTGCTCTTTGTGGTTGGATCTACTCGAGTAGATCCAACCACAAAGAGCATTTTT-3' \\
shc013 & Empty vector \\
\hline
\end{tabular}

sequences sh3810 and sh10819 (Table 1) and, as control, shc013 (empty vector) (plasmids maps are provided in Supplemental Figure S1). RL cells were transduced with lentivector particles carrying these constructs produced by the INSERM UMR1037 vector facility (Cancer Research Center of Toulouse, Toulouse, France). After subcloning of transduced cells and puromycin selection, the subclones specified in the text were used.

\section{Gene Expression Analysis}

RNA was extracted from cells grown either in suspension or in MALC. cDNA were prepared from $200 \mathrm{ng}$ of RNA per sample, and hybridized to GeneChip Human Genome U133 Plus 2.0 Affymetrix (Santa Clara, CA) microarrays (ProfileXpert, Lyon, France). Raw data corresponding to both experiments (MALC\#2D and quiescent\#cycling) are available on the NCBI Gene Expression Omnibus website (http://www.ncbi.nlm.nih. gov/geo; accession number GSE41856). Additional raw data files from purified germinal center cells (GC) $(n=10)$, FL cells purified from biopsies ( $n=38$ ), and five B-EBV lymphoblastoid cell lines were downloaded from the NCBI GEO website (GEO dataset GSE12195 ${ }^{15}$ ). Raw data were analyzed using robust multiarray average algorithms, then normalized by dChip (http://www.hsph.harvard.edu/cli/complab/dchip, last accessed September 15, 2012), $\log 2$ converted and collapsed to 20,606 unique genes with Gene Set Enrichment Analysis (GSEA, http://www.broadinstitute.org/gsea, last accessed September 15, 2012). The 612 experimental genes that were differentially expressed by cells from MALC (fold change $\geq 2, P$ value $<0.05$ versus cells in suspension) were analyzed with AutoCompare ${ }^{16}$ (Fred's Softwares, AutoCompare_win-400.zip, https://sites.google.com/site/fred softwares/products/data-mining, last accessed September 20, 2012). Expression levels of genes shared by reference pathways and experimental gene set were compared between sample groups as specified in the text. For these comparisons, expression levels were normalized and heat maps were generated by Genesis software version 1.7.6 (Genomics and Bioinformatics Graz, http://genome.tugraz.at/genesis client/genesisclient_download.shtml, last accessed October 1, 2012). Significantly differently expressed genes were defined according to the false discovery rate-corrected Q-value.
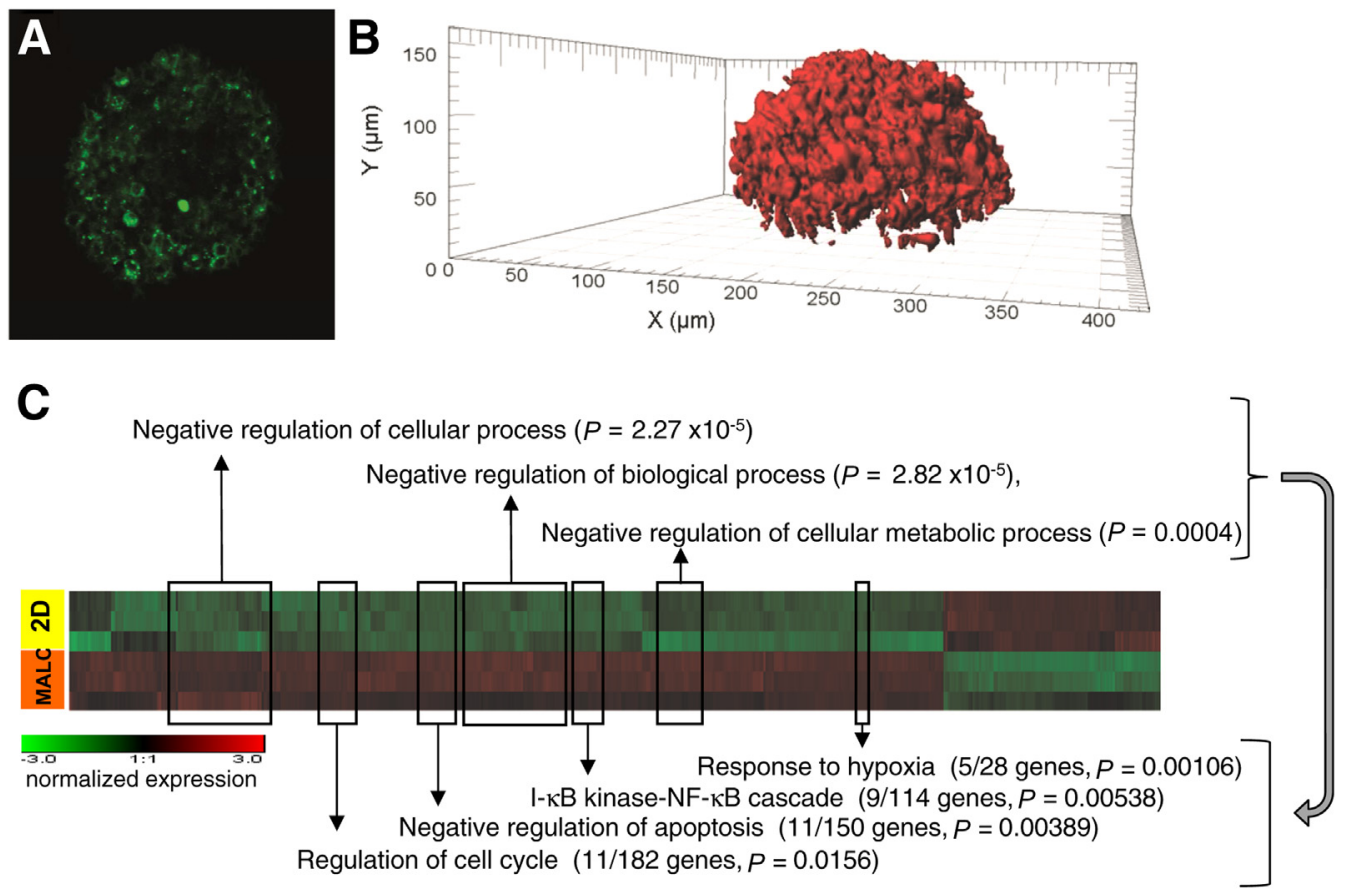

Figure 1 MALC imaging, modeling, and gene expression. A: Fluorescence image of PKH67 MALC was captured by two-photon microscopy 2 days after transfer. B: Analysis and 3D reconstitution were performed with Imaris version 3.1 3D software. C: Heat map represents the clustering of genes deregulated in RL cells cultured in suspension (2D) or as aggregates (MALC). 
Table 2 List of Specific Pathways with the Corresponding Genes Represented by the Analyzed 612 Genes

\begin{tabular}{|c|c|c|c|}
\hline $\begin{array}{l}\text { Response } \\
\text { to hypoxia }\end{array}$ & 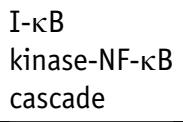 & $\begin{array}{l}\text { Negative } \\
\text { regulation } \\
\text { of apoptosis }\end{array}$ & $\begin{array}{l}\text { Regulation of } \\
\text { cell cycle }\end{array}$ \\
\hline BNIP3 & CFLAR & $B C L 2 A 1$ & ATM \\
\hline$C D 24$ & HTR2B & BNIP3 & CDC25A \\
\hline CXCR4 & IRAK2 & BNIP3L & $C D C 45 L$ \\
\hline EGLN1 & LGALS1 & CFLAR & $C D C 6$ \\
\hline \multirow[t]{7}{*}{ VEGFA } & LITAF & FAIM3 & CDKN1B \\
\hline & МАРЗКЗ & $H R K$ & FOXN3 \\
\hline & SQSTM1 & NOL3 & GADD45A \\
\hline & TNFAIP3 & NOTCH2 & HEXIM2 \\
\hline & TRAF5 & TNFAIP8 & NOTCH2 \\
\hline & & TNFRSF10D & SESN1 \\
\hline & & VEGFA & TIPIN \\
\hline
\end{tabular}

\section{Statistics}

Comparisons of datasets or gene expression levels between the specified groups of samples were based on two-sided Student's $t$-test of paired samples or of groups of unequal variance, according to the datasets. As specified in the text, $P$ values of $<1 \%$ or $<5 \%$ were considered significant. Gene enrichment analysis was based on hypergeometric distributions and Bonferroni corrections for multiple comparisons. $^{17}$

\section{Results}

\section{Growth in MALC Impacts Gene Expression}

We produced MALC from the RL cell line and maintained these for 3 weeks by in vitro cell culture. In general, MALC were visible to the eye and routinely reached volumes of about $30 \mathrm{~mm}^{3}$ within 3 weeks of culture. Visualization of 3-day-old MALC from PKH67-stained RL cells by biphoton microscopy showed oblate spheroids composed of a dense and homogeneous cell population (Figure 1, A and B). Immunohistochemistry of 10-day-old MALC revealed a $\mathrm{CD} 20^{+}, \mathrm{CD}_{10}{ }^{+}, \mathrm{CD}^{-}$, and $\mathrm{CD}^{-} 4^{-}$phenotype that was similar to that seen in two-dimensional (2D) cultures and typical of FL cells (data not shown).

We then investigated the gene expression pattern of cells from this 3D structure. mRNA from RL cells grown either in conventional 2D (exponential phase) or in MALC (10 days culture) were isolated and hybridized on Affymetrix microarrays. Comparison of gene expression patterns in both conditions revealed that $>7000$ genes were differentially expressed in MALC $(P<0.05), 612$ of which displayed significant changes of expression level ( $>2$-fold, both up and down) (Figure 1C). The functional significance of the 612 genes most differentially expressed by MALC cells was analyzed by using AutoCompare for matches with the Gene Ontology's (GO) biological process compendium. As a whole, these genes were significantly involved in negative regulation of cellular process (38 genes, $\left.P=2.27 \times 10^{-5}\right)$, negative regulation of biological process $(39$ genes, $P=$ $\left.2.82 \times 10^{-5}\right)$, negative regulation of cellular metabolic process (18 genes, $P=0.0004)$, and negative regulation of apoptotic process (10 genes, $P=0.002)$. More specifically, these 612 genes were involved in response to hypoxia (5 genes, $P=0.00106), I-\kappa B$ kinase $/ N F \kappa-B$ cascade (9 genes, $P=0.00538)$, negative regulation of apoptosis (11 genes, $P=0.00389)$, and regulation of cell cycle (11 genes, $P=0.0156$ ) (Figure $1 \mathrm{C}$ ). These genes are listed in Table 2.

Thus, FL cells could stably grow in tridimensional aggregates. In such conditions, they displayed a distinct gene expression pattern that reflected adaptation to hypoxia, induction of prosurvival pathway, and an antiproliferative status, the latter being expected from other 3D culture models.

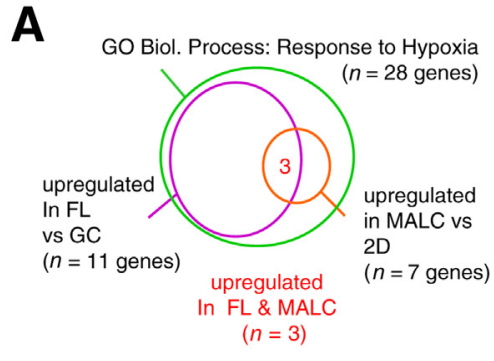

C

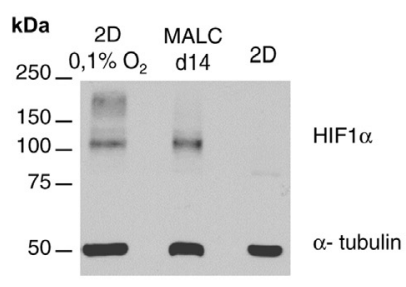

B
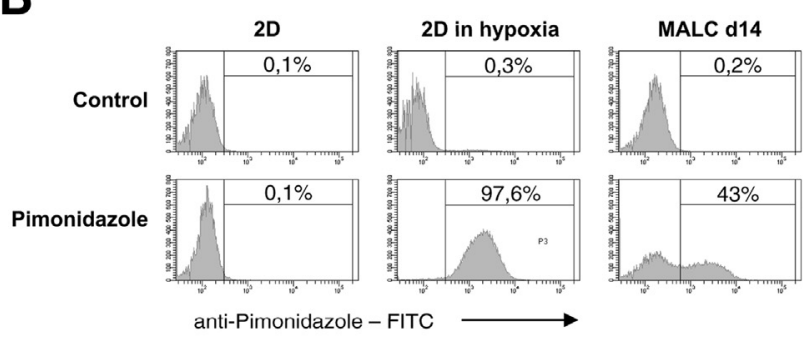

Figure 2 Response to hypoxia. A: Venn diagram represents
D

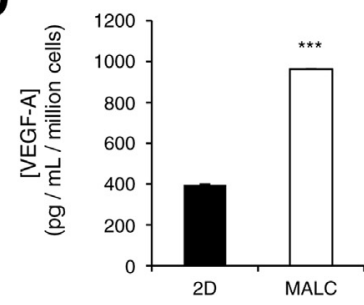
genes included in the response to hypoxia $\mathrm{GO}$ biological process acquired by MALC, compared to $2 \mathrm{D} \mathrm{RL}$, and by $\mathrm{FL}$ nodules, compared to normal GC. B: Pimonidazole staining in $\mathrm{RL}$ cells grown in $2 \mathrm{D}$ normoxia, 2D hypoxia, or in MALC. Analysis was performed with flow cytometry. Additional pimonidazole staining was realized by immunohistochemistry. C: Western blot analysis of HIF1A was performed with protein extracts from $\mathrm{RL}$ cells grown in $2 \mathrm{D}$ normoxia, 2D hypoxia, or in MALC. D: ELISA dosage of VEGFA in 2D normoxia or in MALC. ${ }^{* *} P=0.001$. 
Table 3 Comparison of Genes Up-Regulated Using Gene Signature Response to Hypoxia According to G0-Biological Process Database

\begin{tabular}{llll}
\hline All & FL vS GC & MALC vs 2D & Intersection \\
\hline ALAS2 & ARNT2 & BNIP3 & CD24 \\
ANG & BNIP3 & CD24 & EGLN1 \\
ARNT2 & CD24 & CXCR4 & VEGF \\
BNIP3 & EGLN1 & EGLN1 & \\
CD24 & EPAS1 & PLOD1 & \\
CHRNA7 & HIF1A & SMAD3 & \\
CHRNB2 & HSP90B1 & VEGF & \\
CLDN3 & NARFL & & \\
CREBBP & PLOD2 & & \\
CXCR4 & SMAD4 & & \\
EGLN1 & VEGF & & \\
EGLN2 & & & \\
EP300 & & & \\
EPAS1 & & & \\
HIF1A & & & \\
HSP90B1 & & \\
MT3 & & \\
NARFL & & \\
NF1 & & \\
PDIA2 & & \\
PLOD1 & & \\
PLOD2 & & \\
PML & & \\
SMAD3 & & \\
SMAD4 & & \\
TGFB2 & & \\
VEGF & & \\
\hline
\end{tabular}

\section{MALC Models Hypoxia Occurring in FL}

We first asked whether such conditions might be representative of authentic FL nodules, in terms of molecular profile. To assess this, we looked for the gene signature response to hypoxia in MALC, and compared it with the one of FL cells from biopsies relative to normal GC. In this aim, we downloaded transcriptomes from a single study comprising such samples ${ }^{15}$ and compared the expression level of the 28 genes defining response to hypoxia according to the GO biological process database. Seven of these 28 genes were differentially up-regulated in MALC versus 2D cultures $(P<0.01)$, including the above-mentioned 5 genes (Figure 1C) with fold change $>2$ and $P$ value $>0.05$ (Table 2). In addition, 11 of the 28 genes were also significantly up-regulated $(P<0.01)$ in FL cells relative to normal GC (Supplemental Figure S2), three of which were upregulated and shared with MALC (Figure 2A and Table 3).

This suggested that by culturing FL cell lines in 3D, they acquire a gene expression profile closer to the one observed in FL biopsies.

The next point was to investigate whether this gene signature of response to hypoxia actually reflected the presence of hypoxic conditions in MALC. RL cells were grown in 2D normoxic or hypoxic conditions, and in MALC. Hypoxia was determined in these samples through flow cytometry-based analysis of hypoxic cells following the pimonidazole assay (Figure 2B). This experiment showed that the classic 2D cultures do not comprise hypoxic cells unless they are maintained for $48 \mathrm{~h}$ in hypoxic chambers. By contrast, nearly half of the cells were in hypoxia when grown in MALC. Further immunohistochemistry of pimonidazole-stained MALC showed that hypoxic cells were mostly located in the core of MALC (Figure 2B), hence the gene signature of MALC reflected the sensing of hypoxic conditions in the center of MALC. Because adaptation to hypoxic conditions usually involves stabilization of the HIF1A protein, ${ }^{18}$ we asked whether HIF1A was present in the cell lysates from MALC. The Western blots showed that HIF1A protein in MALC was expressed to the same extent as in 2D culture submitted to severe hypoxia conditions $\left(0.1 \% \mathrm{O}_{2}\right)$ (Figure $\left.2 \mathrm{C}\right)$. Interestingly, confluent cell cultures did not display HIF1A expression (data not shown). Furthermore, because HIF1A protein induces the production of proangiogenic factors such as VEGFA, ${ }^{19}$ we asked whether this also occurs in MALC. VEGFA production was found to be increased in MALC relative to $2 \mathrm{D}$ cultures (Figure 2D). Thus, a functional pathway induced by hypoxia was identified in MALC.

\section{NF- $\kappa B$ Is Found Activated in MALC}

The NF-кB pathway is reportedly found activated in nonHodgkin lymphoma cells, ${ }^{20}$ so we wondered whether this feature was also recovered in the MALC model. The abovedepicted gene expression signature of MALC (Figure 1C) encompasses up-regulation of a set of nine genes corresponding to $I-\kappa B$ kinase $N F \kappa B$ cascade. At this point, we wondered whether this activation pattern might be found in FL nodules. To address this possibility, we compared the gene signature of MALC versus 2D with the one of FL versus normal GC cells (see above) in terms of the 102 genes involved in the $N F-\kappa B$ cascade, because they are listed in the GO biological process compendium. Sixteen of these 102 genes were differentially regulated in MALC versus $2 \mathrm{D}(P<0.01)$. In addition, we found that 66 of the $102 N F-\kappa B$ cascade genes were significantly $(P<0.01)$ up-/down-regulated in FL nodules relative to normal GC (Supplemental Figure S3). Seven of these genes were similarly up-/down-regulated in both MALC and FL samples, six of them being up-regulated; PTPLAD1 is the only down-regulated gene in FL as in MALC (Figure 3A, Table 4). Of note, these $65 N F-\kappa B$ cascade genes were also differentially expressed by the constitutively activated BEBV cell lines. ${ }^{21,22}$ Furthermore, among the genes deregulated by both MALC and FL cells, PTPLAD1, CASP8, TNFAIP3, and CFLAR are wired through a functional network of protein interaction defined as $I-\kappa B$ kinase $/ N F-\kappa B$ cascade by the STRING database (http://string-db.org, last 


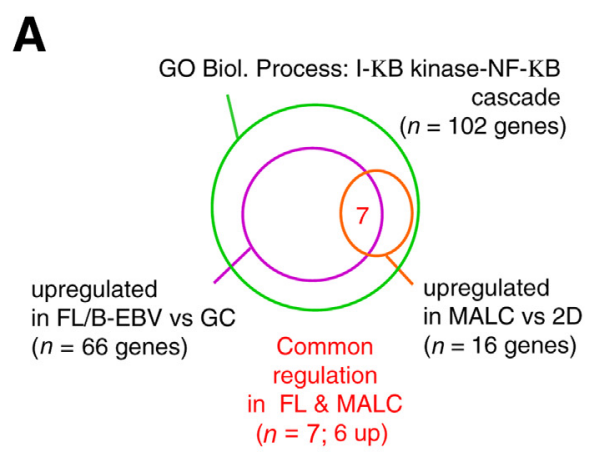

C
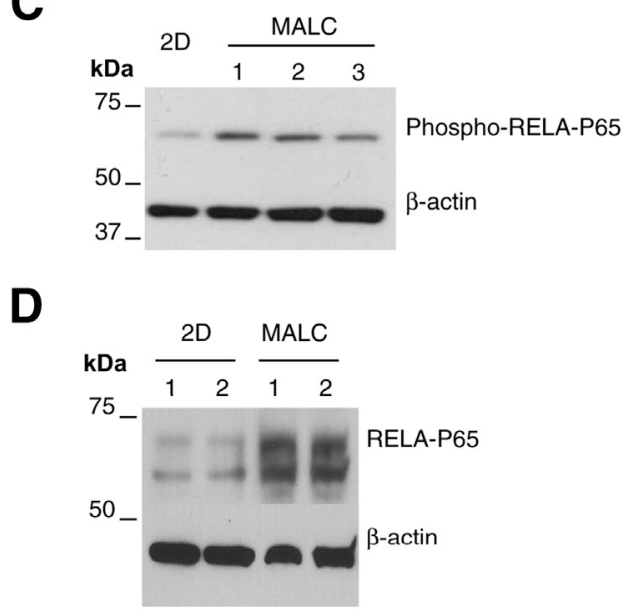

B
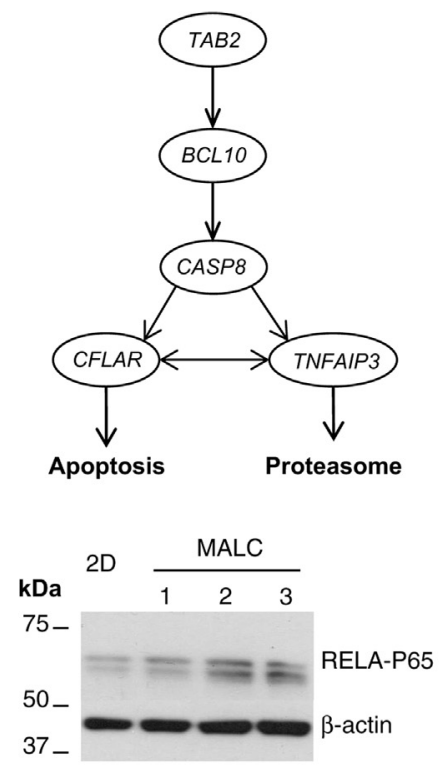

E

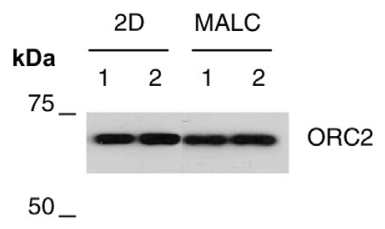

Figure $3 \quad \mathrm{NF}-\kappa \mathrm{B}$ pathway activation in MALC. A: Venn diagram represents genes included in $I$ - $\kappa B$ kinase/NF- $\kappa B$ cascade $\mathrm{GO}$ biological process, regulated in a similar manner in MALC (compared to RL grown in 2D), and in FL nodules (compared to normal GC). B: Functional interaction network part of NF- $\mathrm{KB}$ pathway. C: Western blot analysis of total and phosphorylated (Ser536) forms of RELA-P65 in RL grown in suspension and in MALC (three samples). D: Western blot analysis of RELA-P65 in nuclear extracts of RL grown in suspension or in MALC (two samples) is on the left. Nuclear protein control of this fraction is shown on the right with ORC2 expression, analyzed by Western blot. E: ICAM1 expression in MALC cells relative to $2 \mathrm{D}$ was analyzed by flow cytometry. ${ }^{* *} P=0.001$. accessed October 10, 2012) (Figure 3B). These genes are listed in Table 4.

We were thus prompted to check whether the NF- $\kappa B$ pathway was really activated at the cellular level. To this aim, we analyzed the phosphorylation status and nuclear translocation of RELA-P65 protein in RL cells grown either in suspension or in MALC. We found that both total RELAP65 and its Ser536-phosphorylated form were accumulated in MALC, compared to 2D culture (Figure 3C). In addition, the RELA-P65 protein was more abundant in the nuclear fraction of cells grown in MALC than in the same nuclear fraction of cells grown in 2D (Figure 3D) (the quality control for cell fractionation is shown in Supplemental Figure S4). Finally, we investigated the expression of ICAM1, a protein regulated by the NF- $\kappa \mathrm{B}$ pathway. ${ }^{23} \mathrm{We}$ found that, indeed, ICAM1 was overexpressed in MALC relative to $2 \mathrm{D}$ cultures (Figure 3E).

Thus, a functional NF- $\kappa B$ pathway was found in MALC. This suggests that by culturing lymphoma cells in aggregates, we induce a proinflammatory phenotype.

\section{MALC Growth Induces a Cell-Cycle Exit}

We next investigated cell-cycle regulators in MALC versus $2 \mathrm{D}$ as well as in FL versus normal GC. Thus, $C D K N 1 B$, $C D T 1, D D B 1, H C F C 1, P K M Y T 1, P P M 1 G$, and $U B E 2 C$, all were similarly deregulated in both MALC (relative to 2D) and in the FL biopsy samples (relative to normal GC) (Figure 4A, Supplemental Figure S5, and Table 5): $C D K N 1 B$ was the only one up-regulated in MALC as in FL; the others genes were all underexpressed in both groups. This transcriptome profile was highly suggestive of a low proliferation rate.

These results encouraged us to investigate possible differences in terms of cell proliferation between MALC and 2D culture. The volume of MALC increased with time (Figure 4B). During the first week of in vitro culture, cells from MALC grew quickly but slower than in 2D (mean doubling time of 42 hours, versus 31 hours, respectively), and increased from 10,000 cells at day 0 to roughly 600,000 at day 7. After 1 week, MALC proliferation was sustained with a mean doubling time of 7 days. Along with the culture, however, the cell death rate remained consistently below $10 \%$. Cell cycle, when analyzed by BrdU/propidium iodide double staining, revealed that cells from MALC accumulated in the G0/G1 phase after 7 days of culture, whereas their S-phase decreased (Figure 4C). We hypothesized that this might result from cell-cycle exit rather than G1/S blockade, and thus tested this by high-resolution cellcycle analysis of Ki-67/7-AAD double staining. We found a progressive increase of cells with the 7-AAD ${ }^{\text {diploid }}$, $\mathrm{Ki}-67^{\text {negative }}$ phenotype revealing accumulation of quiescent cells in MALC. Quiescent cells represented $49 \%$ of all cells 
Consequences of Aggregated Lymphoma Growth

Table 4 Comparison of Genes Up-Regulated Using Gene Signature NF- $K B$ Cascade According to the G0 Biological Process Database

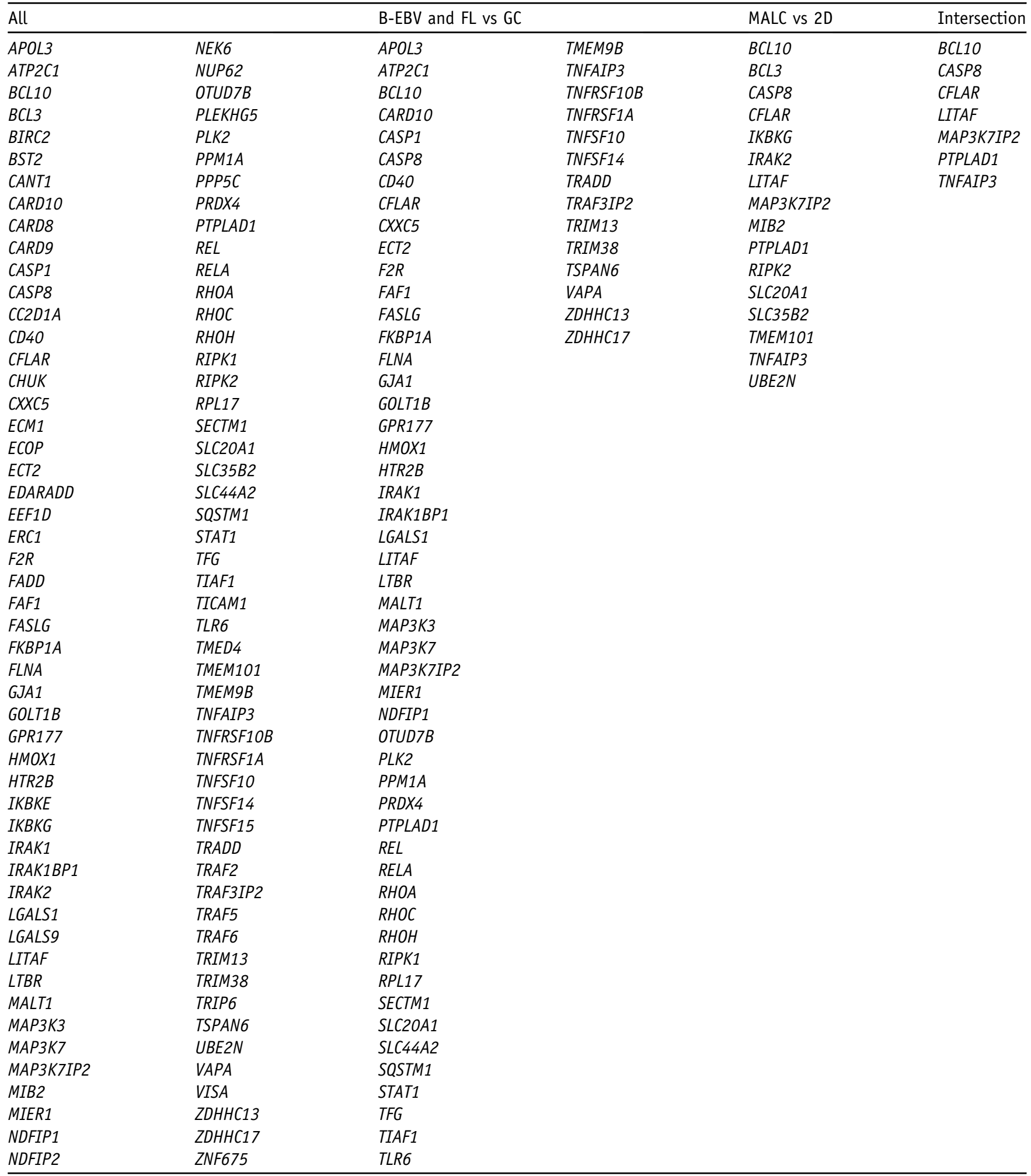

in 3-week-old MALC (Figure 4D), in contrast to confluent cell cultures, which did not contain quiescent cells (data not shown). Loss of Ki-67 expression without associated necrosis was confirmed by immunohistochemistry in MALC (Figure 4D). In addition, both P27 (CDKN1B) and P21
(CDKN1A) regulators of quiescence entry in fibroblasts ${ }^{24,25}$ were more abundant in cells from MALC than in 2D (Figure 4E). Thus, growth in aggregates resulted in a dramatic decrease in cell proliferation and entry into quiescence. 
Table 5 Comparison of Cell-Cycle Regulators in MALC

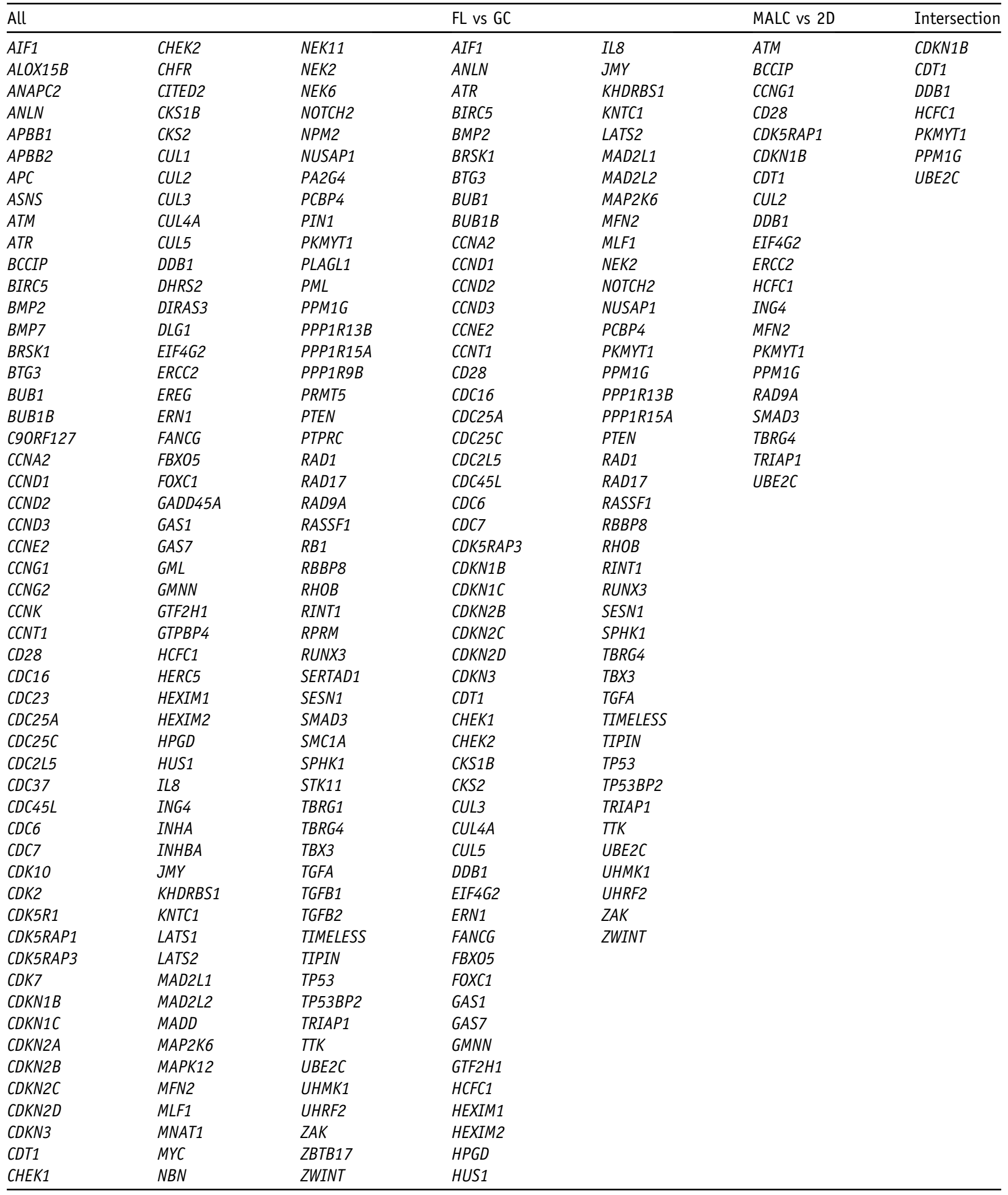

Because hypoxia induces quiescence in hematopoietic stem cells ${ }^{26}$ we questioned whether the quiescent MALC cells arose by adaptation to hypoxic conditions. RL cells were cultured for 2 days in either hypoxic or normoxic conditions and were analyzed for cell-cycle status as above. The hypoxic cultures comprised three times more quiescent cells than the normoxic cultures did (Figure 4F). Along with the response to hypoxia, stabilization of the 

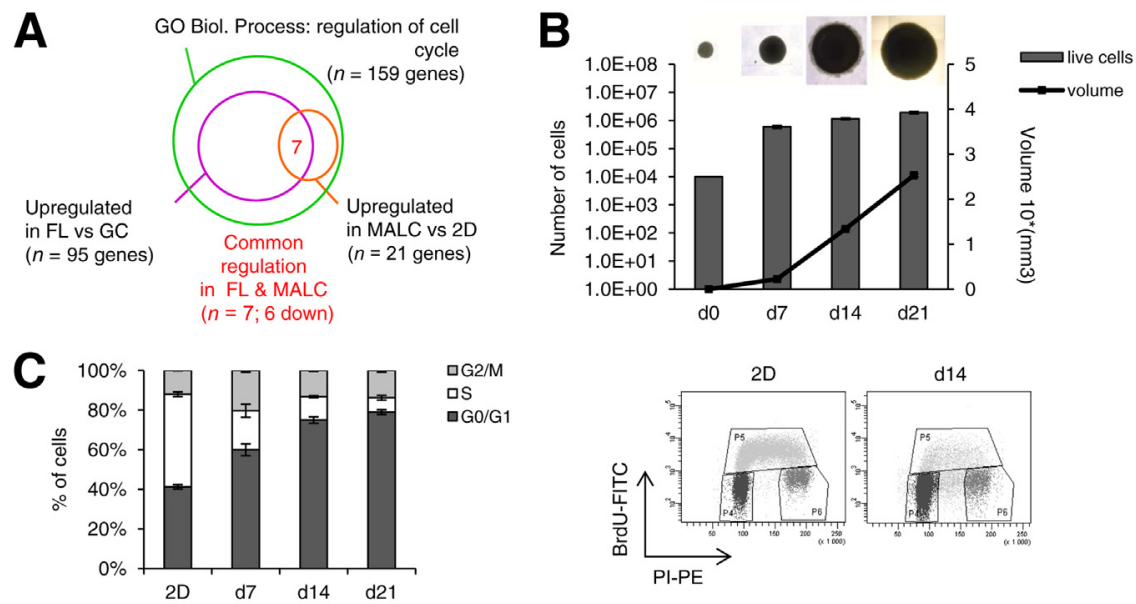

D
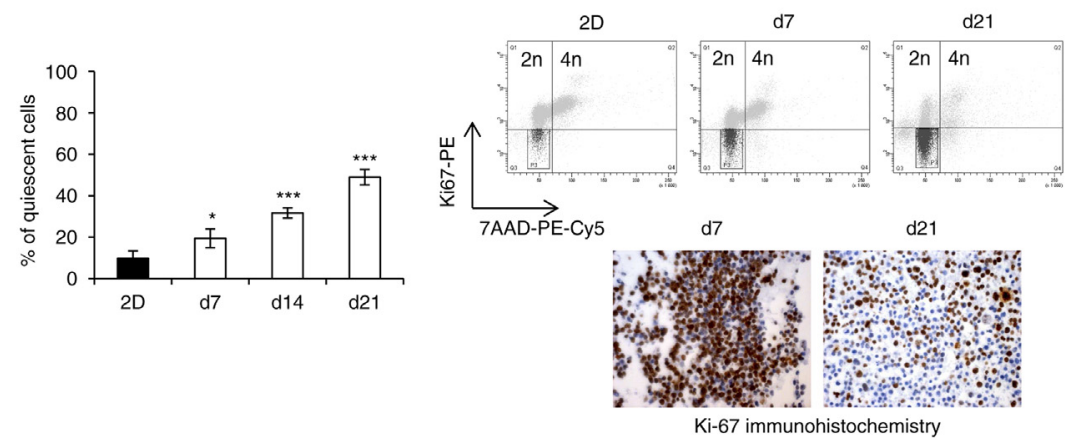

E

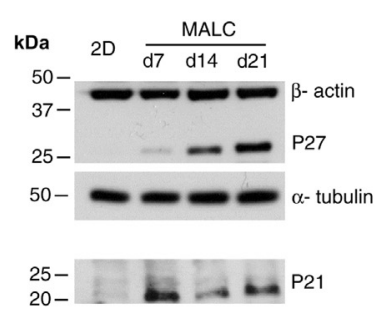

$\mathbf{F}$

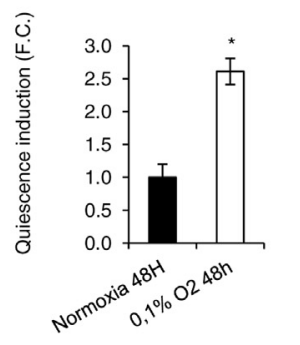

G

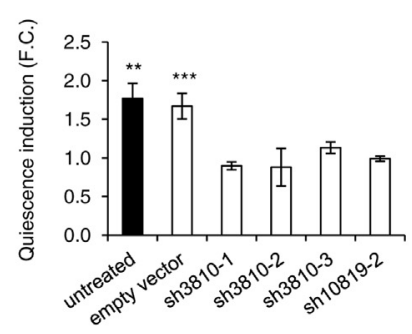

Figure 4 Negative regulation of cell cycle. A: Venn diagram represented genes included in regulation of cell cycle $\mathrm{GO}$ biological process, regulated in a similar manner in MALC (compared to $\mathrm{RL}$ grown in 2D), and in FL nodules (compared to normal GC). B: Number of cells per MALC was evaluated by trypan blue counting, and the volume was calculated using the formula described in Materials and Methods, at different culture times. C: Cell-cycle regulation in 2D RL and MALC was studied by BrdU/propidium iodide co-staining. D: Quiescence entry of MALC cells was quantified by high-resolution cell-cycle analysis. Quiescence was also measured by immunohistochemical staining for KI-67 at day (d) 7 and day 21. E: Western blot analysis of P27 and P21 was performed with protein extracts from $2 \mathrm{D}$ RL in suspension and from MALC at days 7, 14, and 21. F: Quantification of quiescence entry in RL cells grown in $2 \mathrm{D}$ normoxia and 2D hypoxia. G: Effects of $\mathrm{CoCl}_{2}$ in 2D RL cells: wild type (ATCC), transduced with empty vector, and transduced with HIF1A shRNA (sh3810-1, 3810-2, 3810-3, and sh10819-2). ${ }^{*} P<0.05, * * P$ $<0.01$, and $* * * P<0.001$. F.C., fold change; PI-PE, propidium iodide - phycoerythrin.
HIF1A protein mediates cell-cycle arrest in mouse embryonic fibroblasts and splenic B lymphocytes. ${ }^{27}$ Thus, we investigated the role of HIF1A in the quiescence of MALC cells. RL cells grown in suspension were treated with the HIF1A protein stabilizer $\mathrm{CoCl}_{2}$, and the induced quiescent cells were measured. First, $\mathrm{CoCl}_{2}$-treated RL cells comprised twice as many quiescent cells as in the untreated counterpart. By contrast, $\mathrm{CoCl}_{2}$-treated $\mathrm{RL}$ cell clones previously transduced with various shRNA targeting the HIFlA gene did not enter into quiescence (Figure 4G). Altogether, these results suggest that, in MALC, hypoxia, through a HIF1A-dependent mechanism, regulated cell-cycle exit and subsequent MALC expansion.

\section{Gene Expression Changes and Their Functional Consequences in a Quiescent Cell Subpopulation}

On the basis of segregation between cycling and quiescent cells, we hypothesized that the latter displayed specific changes in gene expression profile, compared to the former, and that these changes might account for chemoresistance.

Thus, MALC were sorted by flow cytometry after double staining for pyronin Y/Hoechst 33342, yielding purified quiescent cells of pyronin $\mathrm{Y}^{\text {dull }}$, Hoechst $33342^{\text {diploid }}$, and $\mathrm{Ki}-67^{\text {dull }}$ phenotypes as well as their cycling counterparts (Figure 5A). In the quiescent cell fraction, $>80 \%$ of cells were KI-67 negative. These cells recovered full proliferative potential after 3 days (Figure 5B). The transcriptomes of quiescent and cycling cells were then produced and analyzed by Affymetrix microarrays as above: 4273 genes were differentially expressed by quiescent cells relative to the cycling ones. As illustrated in Table 6, the most significant changes involved negative regulation of proliferation, overexpression of drug transporters, tolerance to DNA damage, and inhibition of apoptosis. Moreover, the major doxorubicin $\operatorname{target}^{28}$ topoisomerase II- $\alpha$ was strongly (10-fold reduction) down-regulated at both mRNA (Table 6) and protein levels (data not shown); CHEKI was also down- 

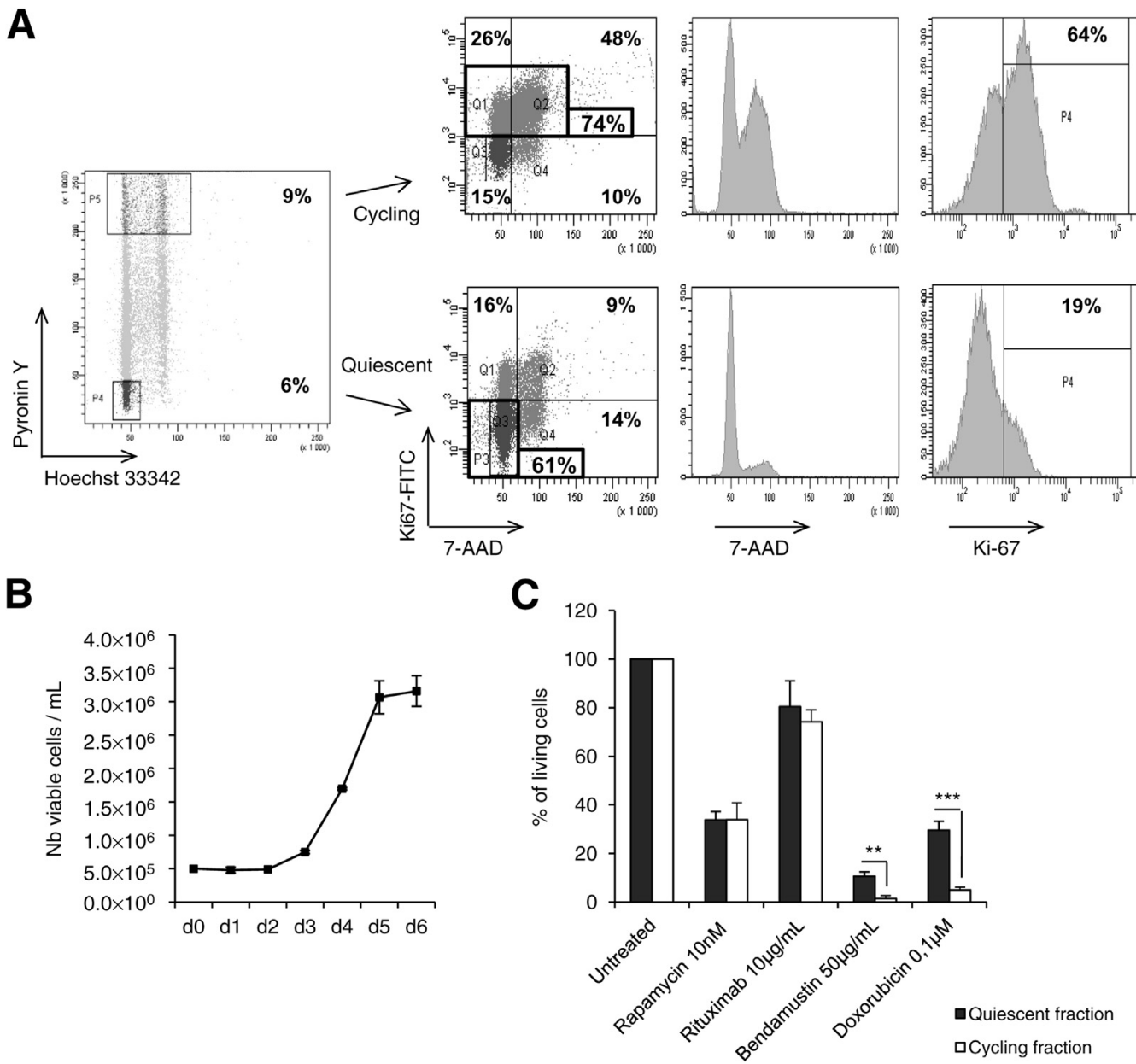

Figure 5 Entry to quiescence and chemoresistance in MALC. A: Sorting efficacy of Hoechst 33342/pyronin staining. B: Growth potential of quiescent cells. C: Differential sensitivity of quiescent and proliferating cells to drugs. ${ }^{* *} P<0.01,{ }^{* * *} P<0.001$.

regulated at the protein level (data not shown). All these changes in quiescent MALC cells suggest a coordinated process converging toward protection and survival. To check whether quiescent cells actually were more chemoresistant, we compared the sensitivity of these and cycling cells to the FL drugs doxorubicin, rituximab, bendamustine, and rapamycin. The quiescent cells were more resistant to doxorubicin and bendamustine, but not to rituximab or rapamycin (Figure 5C).

\section{Sensitivity of MALC Cells to NK Cells}

Finally, we asked whether 3D organization could modulate FL cell resistance to NK cells. Thus, we performed $\mathrm{Cr}^{51}$ release assay by coculturing cells either dissociated from MALC aggregates, or in suspension with NK cells. A dramatic decrease in sensitivity of the former to NK cells at each effector-to-target ratio was indeed observed (Figure 6A). However, by using anti-CD107A, we found no differences between NK cells cultured with 3D cells and NK cells cultured with 2D cells, suggesting that NK degranulation was similar (Figure 6B). Moreover, we found no differences between 3D and 2D FL cells for the expression of Fas receptor as well as HLA class I molecules (HLA-A, $-\mathrm{B},-\mathrm{C}$, and -E) (Figure 6C).

\section{Discussion}

This study depicts for the first time a method for in vitro 3D culture of FL cells. This method sets up appropriate conditions to produce stiff, spheroid-like aggregates growing stably for $>3$ weeks. The resulting MALC show interesting characteristics such as compatibility with immunohistochemistry and biphoton microscopy imaging, as well as capacity for drug testing. Our study indeed shows that MALC represents an invaluable model for screening new genotoxic drugs and therapeutic monoclonal antibodies in lymphoma, because spheroids have been used for preclinical studies of targeted therapy in solid tumors. ${ }^{29,30}$ MALC could be obtained with Raji (Burkitt) and DEAU (diffuse large B-cell lymphoma) cell lines, but not with primary neoplastic B cells (including chronic lymphocytic leukemia) and even some B lymphoma cell lines such as Karpas 422 and DOHH2 (data not shown). 
Table 6 List of Fold Changes in the mRNA Levels of Various Genes in Quiescent MALC Cells

\begin{tabular}{llll}
\hline Family/function & $\begin{array}{l}\text { Gene } \\
\text { symbols }\end{array}$ & Folds & $\begin{array}{l}P \text { value } \\
\text { (Student's } t \text {-test) }\end{array}$ \\
\hline Quiescence & CDKN1B & 2.11 & $1.46 \mathrm{E}-03$ \\
& MXI 1 & 1.96 & $1.50 \mathrm{E}-05$ \\
CDKN1A & 1.32 & $4.96 \mathrm{E}-02$ \\
& TXNDC13 & 1.87 & $2.47 \mathrm{E}-03$ \\
Survival & GSTA1 & 1.65 & $6.13 \mathrm{E}-03$ \\
& GSTM4 & 1.62 & $6.71 \mathrm{E}-03$ \\
& BCL2 & 2.11 & $1.98 \mathrm{E}-04$ \\
& RELA & 1.68 & $2.98 \mathrm{E}-03$ \\
& REL & 1.59 & $5.51 \mathrm{E}-03$ \\
DNA damage tolerance & PKC eta & 1.52 & $2.28 \mathrm{E}-02$ \\
& RELB & 1.5 & $2.52 \mathrm{E}-02$ \\
Drug resistance & CASP3 & 0.73 & $4.83 \mathrm{E}-02$ \\
& CHEK1 & 0.25 & $3.22 \mathrm{E}-05$ \\
& BRCA1 & 0.22 & $1.19 \mathrm{E}-04$ \\
Drug targets & $A B C A 1$ & 1.68 & $3.82 \mathrm{E}-02$ \\
\hline
\end{tabular}

This study shows that the expansion of MALC comprised two steps. During the first week, FL cells actively proliferated and thus MALC grew quickly, although later, cellcycle exit of an increasing rate of MALC cells progressively stopped its growth, as reported for prostate carcinoma cell-derived spheroids. $^{31}$ Isolated $\mathrm{Ki}-67^{\text {negative }}$ cells did overexpress the $C D K N 1 A^{(\mathrm{p} 21)}, C D K N 1 B^{(\mathrm{p} 27)}$, and $M X I-1$ genes that mediate quiescence in various cellular models. ${ }^{32-34}$ In a deterministic interpretation, we view quiescence as an adaptive response to defective nutrient, oxygen, and glucose supply, and the resulting acidosis. Moreover, both experimental studies and mathematical models support the general concept of a metabolic deterioration gradient increasing in the spheroid. ${ }^{35,36}$ Accordingly here, hypoxia was located in the core of MALC. The fact that hypoxia induced cell-cycle exit in 2D cultures suggests its role of quiescence promoter in MALC. We showed that HIF1A mediates this effect, and that HIFIA possibly acts by transcriptionally reactivating genes causing quiescence. This is supported by the regulatory role of HIFIA over P27. ${ }^{37}$ The contribution of hypoxia to the G0 status of MALC cells does not rule out, however, the contribution of additional stresses such as mechanical compression by high cell densities or stiffness because of an extracellular matrix (data not shown).

At the protein level, our study reveals interesting similarities between MALC and FL clinical settings, including reduced $\mathrm{KI}-67$ expression and increased HIF1A expression in biopsies, ${ }^{38,39}$ and elevated VEGFA concentration in serum. ${ }^{40}$ At the genomic level, we have found major differences in terms of gene expression between MALC and 2D cultures, both quantitative (more than 7000 genes) and qualitative (up to 10fold variation). Among these modifications, we have detected several set of genes involved in response to hypoxia, cell proliferation inhibition, and activation of $N F-\kappa B$ pathway by using the AutoCompare software, a method that has been previously validated. ${ }^{41}$ Bioinformatic meta-analysis of transcriptome dataset of Compagno et $\mathrm{al}^{15}$ pinpointed interesting similarities in the gene expression profile between FL biopsies and MALC. Thus, it is possible that previous studies based on conventional (suspension) cultures have underestimated these pathways shown here as conditioned by aggregation. This is obviously the case for the NF- $\kappa \mathrm{B}$ pathway. It is important to note that although NF- $\mathrm{BB}$ has received very little attention in FL compared to diffuse large B-cell lymphoma, ${ }^{20}$ there is some evidence that this pathway is indeed activated in FL tissue samples. ${ }^{42}$ We nevertheless propose here that HIF1A- or $\mathrm{NF}-\kappa \mathrm{B}-$ targeting drugs might represent interesting candidates for FL therapy.

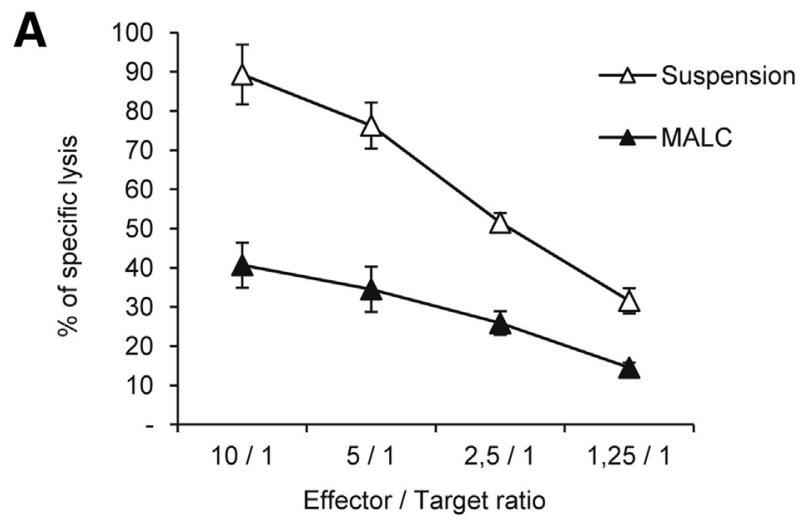

B
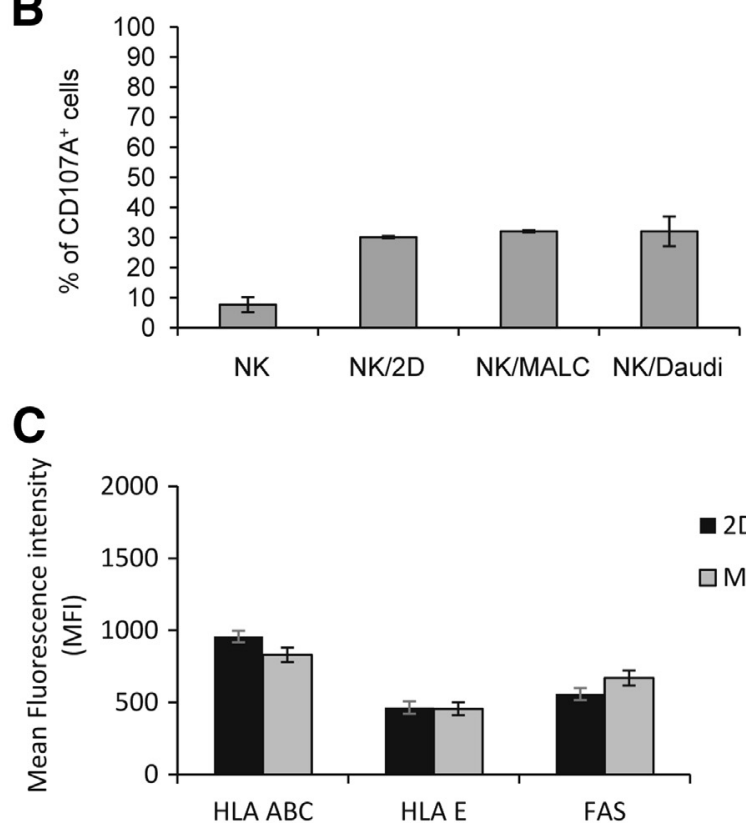

Figure 6 MALC display resistance to NK cell lysis independent of degranulation modification by effector or phenotypic modification on target cells. A: ${ }^{51} \mathrm{Cr}$ release assay. Results are presented as percentages of the specific lysis obtained for the different effector-to-target ratios. B: Degranulation of NK cells cultured for 4 hours either with MALC cells or suspension cells was measured by CD107A staining with PE-Cy5 antibody and detected by flow cytometry. C: HLA-A, - B, - C, and -E and FAS expression in MALC cells relative to $2 \mathrm{D}$ was analyzed by flow cytometry. 
Our study showed that in MALC, the quiescent cells were chemoresistant, not only to doxorubicin, an anthracycline used for years in the treatment of FL, but also to bendamustine, an alkylating agent with promising potential for therapeutic combinations in this disease. Interestingly, with MALC, we did not find significant differences between cycling and quiescent cells in terms of sensitivity to rituximab and mammalian target of rapamycin (mTOR) inhibitor. The high degree of chemoresistance raises several hypotheses related to doxorubicin's mechanism of action. Indeed, after transmembrane penetration, this drug operates through reactive oxygen species production ${ }^{43}$ as well as DNA double-strand breaks because of topoisomerase II/ DNA covalent interaction and subsequent apoptosis. Transcriptome analysis suggested that quiescent cells exhibit defense mechanisms against each intoxication step. Among these, there is overexpression of detoxifying enzymes, together with antiapoptotic signaling through enhanced NF$\kappa \mathrm{B}, \mathrm{BCL} 2$, and protein kinase $\mathrm{C}$ (PKC) pathways. It is important to note that previous studies have already documented in FL tissue samples activation of NF- $\kappa B$ pathway, ${ }^{42}$ up-regulation of PKC expression, ${ }^{44}$ as well as some degree of BCL2 regulation correlated with cell proliferation in parallel with $\mathrm{t}(14 ; 18){ }^{2}$ Furthermore, the topoisomerase II $\alpha$ target of doxorubicin ${ }^{28}$ was decreased. Reduction in DNA damage controllers such as CHEKI and $B R C A 1$ may also increase tolerance to DNA breaks induced by drugs, ionizing radiation, or even endogenous reactive oxygen species production, although it might also favor DNA instability.

Our study shows that MALC acquire resistance to NK cells. This mechanism may contribute to immune escape. However, the mechanism by which MALC become resistant to NK remains to be identified. We were unable to detect significant changes in the expression of molecules involved in the recognition of target by NK cells or in the intoxication process, including Fas expression (Figure 6C) or the expression of PI-9, a granzyme B inhibitor (data not shown). Another hypothesis is that the mechanism could involve a defect in the formation of the immunological synapse as it has been described for FL cells derived from patients and co-incubated with autologous NK cells. ${ }^{45}$ In vivo, it is possible that intrinsic resistance of FL cells to natural immune effectors associates with a defect in immune infiltration, both mechanisms converging toward immune escape. The latter hypothesis is currently under investigation in our laboratory. In the same perspective, the sensitivity of MALC to other immune effectors, such as cytotoxic T lymphocytes, should also be investigated.

To conclude, our study based on MALC, a new in vitro model, shows that aggregated growth of FL tumor cells profoundly affects their proliferation, signaling pathway, cellular defenses, and sensitivity to immune effectors. The MALC model should provide new targets for increasing sensitivity to genotoxic drugs and immune intervention.

\section{Acknowledgments}

We thank the respective institutions for access to the Cancer Research Center of Toulouse's vectorology platform, the Center for Physiopathology of Toulouse-Purpan's flow cytometry facility, the genomic and microgenomic facility ProfileXpert (University of Lyon), and the Department of Pathology of Hospital Purpan (Toulouse).

P.G. realized experiments, analyzed and interpreted data, made the figures, and wrote the paper. C.J. realized experiments and analyzed and interpreted data. J.F. performed data mining and statistical analysis. E.D. and A.B. performed experiments. C.B. and A.S. provided IHC images. C.L. provided samples and interpreted IHC. J.J.F. and G.L. interpreted data and wrote the paper.

\section{Supplemental Data}

Supplemental material for this article can be found at http://dx.doi.org/10.1016/j.ajpath.2013.09.018.

\section{References}

1. Leich E, Salaverria I, Bea S, Zettl A, Wright G, Moreno V, Gascoyne RD, Chan WC, Braziel RM, Rimsza LM, Weisenburger DD, Delabie J, Jaffe ES, Lister A, Fitzgibbon J, Staudt LM, Hartmann EM, Mueller-Hermelink HK, Campo E, Ott G, Rosenwald A: Follicular lymphomas with and without translocation $\mathrm{t}(14 ; 18)$ differ in gene expression profiles and genetic alterations. Blood 2009, 114:826-834

2. Masir N, Campbell LJ, Goff LK, Jones M, Marafioti T, Cordell J, Clear AJ, Lister TA, Mason DY, Lee AM: BCL2 protein expression in follicular lymphomas with $\mathrm{t}(14 ; 18)$ chromosomal translocations. Br J Haematol 2009, 144:716-725

3. Mayer B, Klement G, Kaneko M, Man S, Jothy S, Rak J, Kerbel RS Multicellular gastric cancer spheroids recapitulate growth pattern and differentiation phenotype of human gastric carcinomas. Gastroenterology 2001, 121:839-852

4. Zietarska M, Maugard CM, Filali-Mouhim A, Alam-Fahmy M, Tonin PN, Provencher DM, Mes-Masson AM: Molecular description of a 3D in vitro model for the study of epithelial ovarian cancer (EOC). Mol Carcinog 2007, 46:872-885

5. Wartenberg M, Frey C, Diedershagen H, Ritgen J, Hescheler J, Sauer H: Development of an intrinsic P-glycoprotein-mediated doxorubicin resistance in quiescent cell layers of large, multicellular prostate tumor spheroids. Int J Cancer 1998, 75:855-863

6. Overgaard J: Hypoxic radiosensitization: adored and ignored. J Clin Oncol 2007, 25:4066-4074

7. Dangles-Marie V, Richon S, El-Behi M, Echchakir H, Dorothée G Thiery J, Validire P, Vergnon I, Menez J, Ladjimi M, Chouaib S, Bellet D, Mami-Chouaib F: A three-dimensional tumor cell defect in activating autologous CTLs is associated with inefficient antigen presentation correlated with heat shock protein-70 down-regulation. Cancer Res 2003, 63:3682-3687

8. Feder-Mengus C, Ghosh S, Weber WP, Wyler S, Zajac P, Terracciano L, Oertli D, Heberer M, Martin I, Spagnoli GC, Reschner A: Multiple mechanisms underlie defective recognition of melanoma cells cultured in three-dimensional architectures by antigenspecific cytotoxic T lymphocytes. Br J Cancer 2007, 96:1072-1082

9. Ghosh S, Rosenthal R, Zajac P, Weber WP, Oertli D, Heberer M, Martin I, Spagnoli GC, Reschner A: Culture of melanoma cells in 3dimensional architectures results in impaired immunorecognition by 
cytotoxic T lymphocytes specific for Melan-A/MART-1 tumor-associated antigen. Ann Surg 2005, 242:851-857, discussion 858

10. Timmins NE, Nielsen LK: Generation of multicellular tumor spheroids by the hanging-drop method. Methods Mol Med 2007, 140:141-151

11. Hernandez-Pigeon H, Jean C, Charruyer A, Haure MJ, Titeux M, Tonasso L, Quillet-Mary A, Baudouin C, Charveron M, Laurent G: Human keratinocytes acquire cellular cytotoxicity under UV-B irradiation. Implication of granzyme B and perforin. J Biol Chem 2006, 281:13525-13532

12. Méndez J, Stillman B: Chromatin association of human origin recognition complex, cdc6, and minichromosome maintenance proteins during the cell cycle: assembly of prereplication complexes in late mitosis. Mol Cell Biol 2000, 20:8602-8612

13. Jordan CT, Yamasaki G, Minamoto D: High-resolution cell cycle analysis of defined phenotypic subsets within primitive human hematopoietic cell populations. Exp Hematol 1996, 24:1347-1355

14. Gothot A, Pyatt R, McMahel J, Rice S, Srour EF: Assessment of proliferative and colony-forming capacity after successive in vitro divisions of single human CD34+ cells initially isolated in G0. Exp Hematol 1998, 26:562-570

15. Compagno M, Lim WK, Grunn A, Nandula SV, Brahmachary M, Shen Q, Bertoni F, Ponzoni M, Scandurra M, Califano A, Bhagat G, Chadburn A, Dalla-Favera R, Pasqualucci L: Mutations of multiple genes cause deregulation of NF-kappaB in diffuse large B-cell lymphoma. Nature 2009, 459:717-721

16. Pont F, Tosolini M, Ycart B, Fournié JJ. Edited by Leung HCE. nwCompare and AutoCompare softwares for proteomics and transcriptomics data mining-application to the exploration of gene expression profiles of aggressive lymphomas. Integrative Proteomics. Tech Open Access Publisher, 2012. http://dx.doi.org/10.5772/29555

17. Pont F, Fournié JJ: Sorting protein lists with nwCompare: a simple and fast algorithm for n-way comparison of proteomic data files. Proteomics 2010, 10:1091-1094

18. Bárdos JI, Ashcroft M: Negative and positive regulation of HIF-1: a complex network. Biochim Biophys Acta 2005, 1755:107-120

19. Forsythe JA, Jiang BH, Iyer NV, Agani F, Leung SW, Koos RD, Semenza GL: Activation of vascular endothelial growth factor gene transcription by hypoxia-inducible factor 1. Mol Cell Biol 1996, 16: 4604-4613

20. Davis RE, Brown KD, Siebenlist U, Staudt LM: Constitutive nuclear factor kappaB activity is required for survival of activated B cell-like diffuse large B cell lymphoma cells. J Exp Med 2001, 194: $1861-1874$

21. Laherty CD, Hu HM, Opipari AW, Wang F, Dixit VM: The EpsteinBarr virus LMP1 gene product induces A20 zinc finger protein expression by activating nuclear factor kappa B. J Biol Chem 1992, 267:24157-24160

22. Guasparri I, Bubman D, Cesarman E: EBV LMP2A affects LMP1mediated NF-kappaB signaling and survival of lymphoma cells by regulating TRAF2 expression. Blood 2008, 111:3813-3820

23. Roebuck KA, Finnegan A: Regulation of intercellular adhesion molecule-1 (CD54) gene expression. J Leukoc Biol 1999, 66: $876-888$

24. Rivard N, L'Allemain G, Bartek J, Pouysségur J: Abrogation of p27Kip1 by cDNA antisense suppresses quiescence (G0 state) in fibroblasts. J Biol Chem 1996, 271:18337-18341

25. Perucca P, Cazzalini O, Madine M, Savio M, Laskey RA, Vannini V, Prosperi E, Stivala LA: Loss of p21 CDKN1A impairs entry to quiescence and activates a DNA damage response in normal fibroblasts induced to quiescence. Cell Cycle 2009, 8:105-114

26. Guitart AV, Hammoud M, Dello Sbarba P, Ivanovic Z, Praloran V: Slow-cycling/quiescence balance of hematopoietic stem cells is related to physiological gradient of oxygen. Exp Hematol 2010, 38: $847-851$

27. Goda N, Ryan HE, Khadivi B, McNulty W, Rickert RC, Johnson RS: Hypoxia-inducible factor 1alpha is essential for cell cycle arrest during hypoxia. Mol Cell Biol 2003, 23:359-369
28. Nelson EM, Tewey KM, Liu LF: Mechanism of antitumor drug action: poisoning of mammalian DNA topoisomerase II on DNA by $4^{\prime}-(9-$ acridinylamino)-methanesulfon-m-anisidide. Proc Natl Acad Sci U S A $1984,81: 1361-1365$

29. Weigelt B, Lo AT, Park CC, Gray JW, Bissell MJ: HER2 signaling pathway activation and response of breast cancer cells to HER2targeting agents is dependent strongly on the 3D microenvironment. Breast Cancer Res Treat 2010, 122:35-43

30. Jeong EK, Lee SY, Jeon HM, Ju MK, Kim CH, Kang HS: Role of extracellular signal-regulated kinase (ERK) $1 / 2$ in multicellular resistance to docetaxel in MCF-7 cells. Int $\mathbf{J}$ Oncol 2010, 37: 655-661

31. Sauer H, Ritgen J, Hescheler J, Wartenberg M: Hypotonic Ca2+ signaling and volume regulation in proliferating and quiescent cells from multicellular spheroids. J Cell Physiol 1998, 175:129-140

32. Liu H, Adler AS, Segal E, Chang HY: A transcriptional program mediating entry into cellular quiescence. PLoS Genet 2007, 3:e91

33. Sgambato A, Cittadini A, Faraglia B, Weinstein IB: Multiple functions of p27(Kip1) and its alterations in tumor cells: a review. J Cell Physiol 2000, 183:18-27

34. Ezoe S, Matsumura I, Satoh Y, Tanaka H, Kanakura Y: Cell cycle regulation in hematopoietic stem/progenitor cells. Cell Cycle 2004, 3: 314-318

35. Tindall MJ, Dyson L, Smallbone K, Maini PK: Modelling acidosis and the cell cycle in multicellular tumour spheroids. J Theor Biol 2012, 298:107-115

36. Labarbera DV, Reid BG, Yoo BH: The multicellular tumor spheroid model for high-throughput cancer drug discovery. Expert Opin Drug Discov 2012, 7:819-830

37. Gardner LB, Li Q, Park MS, Flanagan WM, Semenza GL, Dang CV: Hypoxia inhibits G1/S transition through regulation of p27 expression. J Biol Chem 2001, 276:7919-7926

38. Evens AM, Schumacker PT, Helenowski IB, Singh AT, Dokic D, Keswani A, Kordeluk E, Raji A, Winter JN, Jovanovic BD, Holmgren A, Nelson BP, Gordon LI: Hypoxia inducible factor-alpha activation in lymphoma and relationship to the thioredoxin family. Br J Haematol 2008, 141:676-680

39. Stewart M, Talks K, Leek R, Turley H, Pezzella F, Harris A, Gatter K: Expression of angiogenic factors and hypoxia inducible factors HIF 1, HIF 2 and CA IX in non-Hodgkin's lymphoma. Histopathology 2002, 40:253-260

40. Fruchon S, Kheirallah S, Al Saati T, Ysebaert L, Laurent C, Leseux L, Fournié JJ, Laurent G, Bezombes C: Involvement of the Syk-mTOR pathway in follicular lymphoma cell invasion and angiogenesis. Leukemia 2012, 26:795-805

41. Pont F, Familiades J, Déjean S, Fruchon S, Cendron D, Poupot M, Poupot R, L'faqihi-Olive F, Prade N, Ycart B, Fournié JJ: The gene expression profile of phosphoantigen-specific human $\gamma \delta \mathrm{T}$ lymphocytes is a blend of $\alpha \beta$ T-cell and NK-cell signatures. Eur J Immunol 2012, 42:228-240

42. Green MR, Gandhi MK, Courtney MJ, Marlton P, Griffiths L: Relative abundance of full-length and truncated FOXP1 isoforms is associated with differential NFkappaB activity in Follicular Lymphoma. Leuk Res 2009, 33:1699-1702

43. Kuznetsov AV, Margreiter R, Amberger A, Saks V, Grimm M: Changes in mitochondrial redox state, membrane potential and calcium precede mitochondrial dysfunction in doxorubicin-induced cell death. Biochim Biophys Acta 2011, 1813:1144-1152

44. Leseux L, Laurent G, Laurent C, Rigo M, Blanc A, Olive D, Bezombes C: PKC zeta mTOR pathway: a new target for rituximab therapy in follicular lymphoma. Blood 2008, 111:285-291

45. Ramsay AG, Clear AJ, Kelly G, Fatah R, Matthews J, Macdougall F, Lister TA, Lee AM, Calaminici M, Gribben JG: Follicular lymphoma cells induce T-cell immunologic synapse dysfunction that can be repaired with lenalidomide: implications for the tumor microenvironment and immunotherapy. Blood 2009, 114: $4713-4720$ 